\author{
ALEKSANDRA SZYMAŃSKA \\ 0000-0002-3380-5396 \\ Uniwersytet Łódzki \\ Wydział Filologiczny \\ Instytut Rusycystyki \\ Zakład Literatury i Kultury Rosyjskiej \\ 90-226 Łódź \\ ul. Pomorska 171/173 \\ aleksandra.szymanska@uni.lodz.pl
}

\title{
ДОН ЖУАН В СЕТИ. К ВОПРОСУ О КАЧЕСТВЕ ЛИТЕРАТУРНОГО ПРОЦЕССА В ИНТЕРНЕТЕ
}

\author{
DON JUAN ON THE INTERNET: \\ ON THE QUALITY OF DIGITAL LITERATURE
}

В статье подвергается исследованию феномен интернет-графомании на примере романа Марины Масловой Дон Жуан (2004). Выбор текста подиктован нашим интересом к бытованию и трансформациям вечного образа в интернет-пространстве. На примере текста Масловой мы выделили и назвали основные приметы сетературы, такие как: вторичность образов, напряженная и привлекательная интрига, закрученный сюжет, шаблонность, скудный запас литературных образов и мотивов, поэтика повседневности, перманентная динамичность, полиавторность, нарушение дистанции между автором и текстом и др. Анализ романа Дон Жуан позволил нам выявить также механизмы переноса известного мирового образа в интернет-пространство. В связи с этим вопросом мы отметили обращение автора романа лишь к отдельным ситуациям и мотивам истории Дон Жуана, приспособление их к жанру дамского романа, свободное отношение к литературной традиции, лишение образа сюжетной самостоятельности. в Сети.

Ключевые слова: Дон Жуан, интернет-литература, массовая литература, графомания

The aim of the present article is to analyse the phenomenon of graphomania on the Internet, with Marina Maslova's 2004 novel Don Juan as an example. The choice of the text was dictated by the interest in the presence of the eternal image of Don Juan in the Internet space and in the transformations it undergoes there. Taking Maslova's text as an example, the author of the paper identifies and names essential features of digital literature, among others: derivativeness (non-originality) of literary images, a tense and attractive story, a twisted plot, stereotypical devices, a limited stock of literary images and motifs, the poetics of everyday life, permanent dynamism, polyauthorism, violation of the 
distance between the author and the text. The analysis of Maslova's novel makes it possible to identify also the mechanisms of transformations applied to the image of Don Juan in the Internet space. In that connection, it is noted that the discussed writer only takes interest in certain selected situations and motifs from Don Juan's story, adapts them to the genre of the romance novel, displays a free approach to the literary tradition and deprives the eponymous figure of autonomy in terms of plot.

Keywords: Don Juan, digital literature, mass literature, graphomania on the Internet.

Образ Дон Жуана, как известно, является одним из наиболее востребованных писателями вечных образов. С момента своего появления в драме Тирсо де Молины он подвергался многочисленным обработкам. В мировой литературе герой изображен молодым и дерзким испанским идальго, неисправимым соблазнителем и покорителем женских сердец, жертвой женской ветрености, мужем, отцом, больным, постаревшим, оказавшимся в аду. Новые интерпретаторы, пытаясь сделать героя и связанный с ним сюжет интересным для своих современников, вводили в свои произведения отдельные мотивы или, напротив, отказывались от них, часто разрушая мотивную структуру сюжета. Его трактовка во многом была обусловлена характером эпохи и читательскими ожиданиями.

В данной статье предметом нашего интереса станет бытование образа Дон Жуана и связанного с ним сюжета в Интернете. Новый тип общения в свободном пространстве - часто анонимный, лишенный ответственности, интенсивный и эмоциональный - ощутимо повлиял на литературу. Новым типом общения людей в Сети довольно быстро воспользовалась массовая литература, для которой коммуникативная функция Интернета стала одной из ключевых.

С появления неограниченной возможности размещать тексты в интернет-пространстве меняется восприятие слова писатель. Оказывается, чтобы им стать, достаточно быть подключенным к Сети. Таким образом, в один ряд попадают профессиональные писатели, авторы графоманских дешевых романов, блогеры, копирайтеры и авторы, публикующиеся в самиздате. При исчезновении необходимости печатать произведения в прошлое уходит процесс их отбора, а также длительного хранения, которые связаны с понятием элитарности литературы. В такой ситуации особо актуальной оказывается дискуссия о дифференциации по качеству сетевого литературного творчества.

Так, Павел Виноградов, бывший редактор одного из отделов газеты «Невское время», анализируя числовые данные ресурсов для самодеятельного творчества за 2010 год, заметил, что Интернет оказался «идеальным прибежищем для орды бездарных графоманов с манией величия» ${ }^{1}$. Его

${ }^{1}$ См.: П. Виноградов, Литература уходит в сеть, «Невское время» 16.03.2010, [электронный ресурс] https://nvspb.ru/2010/03/16/literatura-uhodit-v-set-41971, [04.07.2018]. 
мнение о сетевых авторах не является спорадическим. Алексей Виноградов в Учебнике о графомании утверждает, что сетература родилась исключительно в графоманской среде ${ }^{2}$. Сергей Корнев, в свою очередь, замечает, что Интернет стал своеобразным «полигоном» для молодых авторов, учащихся ремеслу, или «тихой пристанью» для тех, кому не повезло ${ }^{3}$. Графоманская нужда постоянно сочинять рассматривается как болезнь, которой подвержены люди независимо от пола, возраста и таланта ${ }^{4}$, а публикация трудов в Сети, как вид психотерапии, удовлетворяющий потребность графоманов в общении со своими поклонниками 5 .

Процесс писательства в Сети становится постоянной интеракцией автора со своей аудиторией. Он приносит автору возможность самостоятельно конструировать своего читателя, «приучать» его к своему творчеству, создавать объединения близких по духу людей ${ }^{6}$, а также комментировать свои произведения, и даже скорректировать восприятие своих текстов или сами тексты, согласно ожиданиям читателей.

Конечно, постоянный и неограниченный диалог автора текста с читателями порождает множество опасных ситуаций. Во-первых, писатель становится кем-то в роде наемного работника социума, который зависит от его вкусов и потребностей. Во-вторых, голос автора может стать важнее, чем сам текст. Неограниченный диалог автора с читателем может привести к утрате неоднозначности текста и затушевать его альтернативные прочтения ${ }^{7}$ В-третьих, в погоне за популярностью (часто локальной, не выходящей за пределы сайта), авторы готовы прибегать к разным сетевым трюкам - писать положительные рецензии другим авторам в ожидании ответного гостевого визита или писать анонимные хвалебные рецензии на собственное творчество.

В настоящей статье постараемся продемонстрировать проявления феномена интернет-графомании на примере романа Дон Жуан (2004), который включен его автором - Мариной Масловой - в цикл Сказки ушедшего века,

\footnotetext{
${ }^{2}$ А. Виноградов, Учебник по графомании, 2004, [электронный ресурс] https://www. litmir.me/bd/?b=129901 [04.07.2018].

${ }^{3}$ С. Корнев, «Сетевая литература» и завершение постмодерна. Интернет как место обитания литературы, «Новое литературное обозрение» 1988, № 32, [электронный ресурс] http://magazines.russ.ru/nlo/1998/32/korn.html [04.07.2018].

${ }^{4}$ И. Булкина, Проза «нулевыхх», «Знамя» 2010, № 9, [электронный ресурс] http:// magazines.russ.ru/znamia/2010/9/bu15.html [04.07.2018].

${ }^{5} \mathrm{O}$. Чернорицкая, Самосознание сетевой литературы. Феноменология сетевого авторства, «Топос» 21.03.2005, [электронный ресурс] http://www.topos.ru/article/3393 [04.07.2018].

${ }^{6}$ Как замечает Дмитрий Манин, Интернет «взял на себя функции глобального и круглосуточного салона». См.: Д. Манин, Вместо манифеста, «Сетевая Словесность» 1998, [электронный ресурс] https://www.netslova.ru/teoriya/seteratura.html [04.07.2018].

${ }^{7}$ С. Корнев, «Сетевая литература» и завершение постмодерна..., [04.07.2018].
} 
размещенного на сайте Проза.ру. Анализ романа Масловой позволит нам проследить трансформацию образа и связанного с ним сюжета в условиях интернет-пространства.

Оказывается, что образ Дон Жуана не теряет своей привлекательности для сетевых авторов. Роман Масловой не единственное обращение к известному образу, которое опубликовано исключительно в Интернете. На том же портале Проза.ру можно прочитать пьесу Ирины Мухаметовой Дон Жуан и Дон Кихот (2010), на сайте Стихи.ру - драму Дмитрия Подчуфарова Гибель Дон Жуана (2002). Целый ряд драматических произведений, героем которых является Дон Жуан, можно найти на сайте Театральной библиотеки Сергея Ефимова.

В авторский цикл ${ }^{8}$ Масловой Сказки ушедшего века вошло семь произведений, которые публиковались на сайте Проза.ру на протяжении трех месяцев. Добавим, что это не единственные тексты, которые размещены автором на сайте за это время, т. е. апрель-июнь 2004 года. Количество произведений Масловой, многие из которых определены ей как романы, указывает на одну из отличительных черт сетературы - отвечать потребности современного, подключенного к Сети читателя в постоянно новых ощущениях. Сетевая литература приобретает, таким образом, черты блог-литературы. Писатели, как блогеры, стараются быть как наиболее продуктивными и актуальными, чтобы читатели их не забыли ${ }^{9}$. «Жертвами» погони авторов за популярностью оказываются сами тексты, которые быстро уходят в забвение. В качестве доказательства отметим, что последний комментарий к роману Дон Жуан Масловой относится к 2006 году, т. е. появляется два года спустя после публикации текста.

Доступные в Сети отзывы читателей романа Дон Жуан доказывают нежелание сетевых читателей терять время на чтение толстых книг. В качестве подтверждения приведем одно из читательских замечаний по поводу произведения Масловой:

Мариночка, замечательно получилось, прочитал с большим удовольствием, хотя за один присест не получилось, пришлось отрываться. Но да это не беда, кому удастся прочесть за один присест Войну и мир. У Вас не роман, но повесть и очень удачная. Жалобы на затянутость этой вещи всерьез не принимайте. А вот сюжеты неизвестных Жуанов/Хуанов хотя бы вкратце можно дать отдельным приложением (это для неграмотных и ленивых к розыскам) ${ }^{10}$.

\footnotetext{
${ }^{8}$ Авторским циклом произведения называет сам автор.

${ }^{9}$ С. Корнев, «Сетевая литература» и завершение постмодерна..., [04.07.2018].

${ }^{10}$ [Электронный pecypc] https://www.proza.ru/comments.html?2004/06/17-06 [12.07.2018].
} 
В глаза бросается фамильярное отношение читателя к автору текста, который выступает в роли снисходительного учителя, указывающего на недостатки романа.

Маслова, пользуясь возможностью общения в Сети со своими читателями, жалуется на стилистические и грамматические недостатки своих произведений и указывает на причины их возникновения. Из личного сайта автора узнаем также, в чем заключается общность произведений цикла Сказки ушедшего века ${ }^{11}$ и историю их создания.

Общей тенденцией бесед сетевых авторов с читателями является желание авторов оставаться симпатичными, что сказывается на посещаемости их сайтов. Отметим, что любой посетитель на сайте Проза.ру, который сознательно или случайно открыл текст произведения именуется читателем. С момента публикации первого текста, т. е. с июня 2004 года произведения Марины Масловой открыло 26784 пользователя Интернета. Заметим, что у Владимира Сорокина на том же сайте 21403 читателя. Стоит, однако, отметить, что опубликованные там произведения Сорокина относятся к 2017 и 2018 годам.

Роман Масловой, как и ряд других текстов, публикуемых в Сети, снабжен так называемыми классификаторами, которые указывают на время и место действия, а также на основные мотивы, намекающие на тематику произведения и его жанровую принадлежность. Итак, роман Дон Жуан получил следующие классификаторы: новейшее время, Европа, героиня добивается героя, фиктивный брак, беременность, герой/героиня творческие профессии, любовники, путешествие. Стоит подчеркнуть, что в приведенном списке отсутствует малейший намек на донжуанский сюжет, и даже на его отдельные мотивы. Набор характеристик позволяет, зато довольно легко определить принадлежность текста к женскому сетевому роману.

К основным составляющим женского романа причисляется, между прочим, наличие соответствующей содержанию и жанру обложки. Так, хотя роман Дон Жуан не печатался, на сайте ДамскийКлубLADY можно посмотреть проект обложки к нему. Изображен стул, рядом с которым стоит то ли оставленная, то ли ожидающая появления музыканта гитара - один из атрибутов Дон Жуана. То есть видеоряд обложки никоим образом не нацеливает читателя на тематику, заявленную посредством классификаторов. По проекту обложки заметно желание автора включить свое произведение в богатую литературную традицию и стать ее частью.

\footnotetext{
${ }^{11}$ «Я стала записывать то, что считаю самым важным: не просто события, а чувства, мысли, воспоминания, ассоциации - то, что стоит запомнить и сохранить. Это у каждого - свое. Так стали рождаться сказки ушедшего века», [электронный ресурс] https://www.proza. $\mathrm{ru} /$ avtor/maslovam [12.07.2018].
} 
Наше замечание подтверждает выбор Масловой заглавия, в качестве которого автор употребил имя испанского соблазнителя, рассчитывая, как представляется, на популярность и привлекательность образа, а также эпиграфа - строк из стихотворения Марины Цветаевой: «Не было у Дон-Жуана - Донны Анны». Приведенная фраза ставит под сомнение обретение Дон Жуаном в Донне Анне идеала женственности и любви и является голосом поэтессы в споре о возможности Дон Жуана полюбить по-настоящему. Ссылаясь на авторитетный источник, эксплуатируя классическое наследие, играя с цитатами, Маслова стремится придать своему произведению значимость и идти на встречу вкусам более требовательных читателей.

Однако в тексте произведения вместо традиционных мотивов донжуанского сюжета мы находим полный набор мотивов, характерных для дамского романа. Он, как правило, адресован женской аудитории и представляет взгляд на мужчин, любовь, семью, половые отношения с женской точки зрения.

Обратимся к тексту произведения Масловой, чтобы проиллюстрировать популярные для дамского романа мотивы, а также раскрыть особенности общеизвестного героя в интернет-пространстве.

Роман Масловой не является очередной разработкой донжуанского сюжета. Связь с первоосновой фабулы обнаруживается лишь в употреблении в заглавии имени Дон Жуана и имени центральной героини донжуанского сюжета - Анны. Автор не сохраняет отдельные мотивы легенды, а связь с первоначальной версией осуществляется за счет обращения к донжуанской ситуации. Так, авторской интерпретации подвергается ситуация, которая заключается в безрезультатных поисках Дон Жуаном настоящей любви. Однако Дон Жуан не становится одним из персонажей романа, а объектом научного исследования героев - австрийского психоаналитика Франца и русской переводчицы Анны. Правда, Анна в конце произведения сочиняет роман на основе истории о Дон Жуане, но его содержание приводится лишь в отрывках.

Прием «романа в романе» послужил Масловой для выявления причины любовных неудач Дон Жуана, которую вследствие собственного жизненного опыта, раскрывает ее героиня. Стремясь к привлекательности сюжета, к остроте конфликта и рассчитывая на сенсацию, автор вводит мотив нетипичной сексуальной ориентации известного соблазнителя ${ }^{12}$. Источником испорченных отношений Дон Жуана с женским полом оказывается его гомосексуализм. Роман, сочиненный героиней Масловой, заканчивается сценой убийства Дон Жуаном мужа Анны - Дона Диего. Неожиданным в этой

${ }^{12}$ Мотив латентного гомосексуализма Дон Жуана появился в пьесе Ночь в Валони (1991) французского драматурга Эрика Эмманюэля Шмитта. 
сцене является признание Дон Жуана в любви Дон Диего и отчаяние Анны, узнавшей правду.

После этой сцены становится понятным, что эпиграф из стихотворения Цветаевой предпослан не столько первому роману, сколько второму - введенному в основной текст. Использование фрагмента из стихотворения Цветаевой, в котором ставится под сомнение тезис о способности Дон Жуана любить и обрести в Анне идеал, в качестве доказательства гомосексуализма героя, искажает мысль поэтессы и указывает на непонимание Масловой классической основы истории о Дон Жуане.

Роман Масловой, однако, сосредоточен не столько на мужских персонажах, сколько на судьбе главной героини, представляющей собой трансформацию мифа о «новой русской женщине». История жизни Анны выдержана в духе гламурной эстетики, понимаемой как специфически-образная форма выражения бытия, основанная на принципах гедонизма, ставящая эстетический акцент на роскошь и внешний блеск ${ }^{13}$.

Анна - современная русская женщина, которая, несмотря на свою красоту, блестящие языковые способности, музыкальный талант, начитанность, хорошую работу в издательстве, умение вести домашнее хозяйство не находит счастья в любви. Однажды судьба сталкивает ее с Францем - привлекательным и богатым психоаналитиком из Австрии, который исследует изменение мотивации поступков Дон Жуана в зависимости от эпохи создания образа. Его особенно интересует женский взгляд на проблему. Франц предлагает героине фиктивный брак и работу переводчицы для того, чтобы она смогла уехать в Австрию к своему любовнику Павлу. После приезда в Австрию, героиня понимает, что Павел не готов рисковать устроенной жизнью со своей «фрау», и она полностью отдается новому занятию - переводу на немецкий язык известнейших литературных произведений, посвященных Дон Жуану. Она переводит, между прочим, тексты Мольера, Мюссе, Бодлера, Молины и др.

Анна скоро становится для Франца кем-то вроде советника. Маслова вводит в роман содержание нескольких бесед Анны и Франца по поводу идеи Дон Жуана, в которых слышатся отголоски разных интерпретаций образа - от соблазнителя, который не способен любить, до мужчины, который любит всех женщин. Споры получают соответствующую жанру окраску. Герои ведут их на фоне андалусийской природы. Испанский колорит наряду со страстным романом Анны с танцовщиком фламенко и раскрытием тайны гомосексуализма Франца придают конфликту необходимую остроту.

${ }^{13}$ К. Ю. Точилов, Гламур как эстетический феномен: генезис и исторические модификации. Автореферат диссертации на соиск. уч. ст. канд. филос. наук, Москва 2011, [электронный ресурс] http://www.dissercat.com/content/glamur-kak-esteticheskii-fenomen [18.07.2018]. 
Интересно отметить непоследовательность Масловой в создании образа героини, уподобленной Донне Анне. Ее поведение с мужчинами, убежденность во внешней привлекательности, умение вести флирт, пристрастие к любовным приключениям позволяют увидеть в ней скорее вариант Дон Жуана в юбке, чем Донны Анны.

В финале романа обращение к донжуанской теме вовсе отсутствует. Он представляет собой набор мотивов характерных для «розового романа». Так, читатель узнает подробности совместной, устроенной жизни Анны и Франца в Австрии, получает информацию о романах Анны, разгадку тайны ее беременности, информацию об удочерении ребенка Францем. В конце романа Анна начинает тосковать по своему любовнику, понимая, что жизнь с человеком, который из-за своей сексуальной ориентации не в состоянии выполнить ее ожидания, слишком тяжела. Открытый финал оставляет Масловой возможность продлить историю Анны в случае ее успеха у читателей.

Итак, роман Масловой сохраняет жанрово-тематические каноны массового дамского романа, такие как: напряженная интрига, закрученный сюжет, устойчивый набор типов героев, шаблонный сюжет, поэтика повседневности, заключающаяся в точной фиксации примет действительности, тривиальных явлений обыденной жизни, легкость усвоения текста, не требующая особого литературно-художественного опыта, «одноразовость». Одной из черт массового дамского романа является эксплуатация классического наследия, что может объяснить решение Масловой обратиться к «модному» образу. Образ Дон Жуана, однако, несмотря на усилия Масловой, предстает в его сниженном, бытовом варианте, подчиняясь требованиям жанра и вкусам сетевых читателей.

Сетевая массовая литература, что доказывает анализ романа Масловой, является важным источником информации о жанровых и тематических ожиданиях читателя и об авторских стратегиях.

\section{References}

Bulkina, Inna. “Proza 'nulevykh”'. Znamya, No. 9 (2010). http://magazines.russ.ru/znamia/2010/9/ bu15.html.

Chernoritskaya, Olga. "Samosoznanie setevoi literatury. Fenomenologiya setevogo avtorstva". Topos, (21.03.2005). http://www.topos.ru/article/3393.

Kornev, Sergei. "'Setevaya literatura' i zavershenie postmoderna. Internet kak mesto obitaniya literatury". Novoe literaturnoe obozrenie, No. 32 (1988). http://magazines.russ.ru/nlo/1998/32/ korn.html [04.07.2018].

Manin, Dmitrii. "Vmesto manifesta". Setevaya Slovesnost, (1998). https://www.netslova.ru/teoriya/ seteratura.html. 
Tochilov, Konstantin Yu. Glamur kak esteticheskii fenomen: genezis i istoricheskie modifikatsii. Avtoreferat dissertatsii na soiskanie uchenoi stepeni kandidata filosofskikh nauk. Moskva, 2011. Vinogradov, Aleksei. Uchebnik po grafomanii. 2004. https://www.litmir.me/bd/?b=129901.

Vinogradov, Pavel. "Literatura ukhodit v set". Nevskoe vremya (16.03.2010). https://nvspb. ru/2010/03/16/literatura-uhodit-v-set-41971.

http://www.dissercat.com/content/glamur-kak-esteticheskii-fenomen.

https://www.proza.ru/comments.html?2004/06/17-06.

https://www.proza.ru/avtor/maslovam. 